\title{
Volatile Compounds of Some Blueberries Cultivars Infested with Fruit Fly Ceratitis Capitata
}

\author{
Hasan Hadi Al-khshemawee \\ College of Agriculture, Wasit University, Wasit, Iraq. \\ Corresponding Author: hasan_hadi1984@yahoo.com
}

Received : $12 / 11 / 2021$
Acceptance : 27/11/2021
Available online: $31 / 12 / 2021$

\begin{abstract}
It is important to understand the fruit insect interaction mechanism to developing strategies to control the pests. The Mediterranean fruit fly Ceratitis capitata (Medfly) infested some blueberries Vaccinium spp. cultivars, and their volatile compounds composition of infested fruit of those cultivars has been studied. Head space solid-phase microextraction extractiongas chromatography (SPME-GC/MS) has been used to detect volatiles on these cultivars. First Blush 4514 and Brigitta 1403 Australian cultivars used in this experiment. A total of 119 compounds find form these cultivars. There are a major different volatiles and their structure from infested fruits. HS-SPME released complex volatiles including (butanoic acid-3 methyl-, methy ester, methyl isovalerate, Butanoic acid-3 methyl-, isobutyl acetate, ethanone,2,2-dihydroxy-phenyl ) from First blush and Styrene, and 6-Methyl 1-2,3-dihydro-1,4-oxathine, methyl isovalerate, butanoic acid-3 methyl-, methy ester, ethyl isobutenoate from Brigitta cultivar.
\end{abstract}

Keywords. V.corymbosum, Ceratitis capitata, HS-SPME, GC-MS.

\section{INTRODUCTION}

Ceratitis capitata (Medfly) is an important fly that damage on a huge number of fruits, specially the larvae stage [1]. Fruit flies can be adapt with hard environmental condition, which is attention in zones separate and therefore potentially this zone at risk [2,3]. Using pesticides to control fruit flies were harmful the human and environment [4]. This issue could be more dangerous in fruit production, since many counties rule reduce the use of pesticides. So, before fruit fly damage occurs, some governments tend to limit these problems [5,6].

The host is a key criterion for determining whether pest risk with Medfly must be measured are required to mitigate by management the pest, including blueberries. Blueberries Vaccinium spp. have been the main crop worldwide [7,8]. Blueberries productions are spreading owing to develop new cultivars in different areas [9,10]. Recently, many researches explain how the infested fruit release different type of volatile organic compounds (VOCs). These chemicals decreases or increases during the ripening period of fruits $[11,12,13]$. This study evaluate infested fruit with fruit fly using HS-SPME as a technology for detect hidden infestation of blueberries. The main aim of this study is to identify of volatile organic compounds (VOCs) profiles of infested and non-infested blueberries with Medfly at three times of infestation of larvae.

\section{MATERIALS AND METHODS}

\section{- Insect Culture}

The colony of Medfly was obtained from fruit fly centre (Murdoch University), Australia and the insects were reared in the Laboratory (Murdoch University). The conditions $23^{\circ} \mathrm{C} \pm 2{ }^{\circ} \mathrm{C}, 75 \% \pm 5 \% \mathrm{RH}, 12: 12-\mathrm{h}$ (L:D) were used to reared Medfly. Screen cages ( $40 \mathrm{~cm}$ length $\times 40 \mathrm{~cm}$ height $\times 40 \mathrm{~cm}$ depth) have been used to rearing medfly adults and in each cage contained crystaline yeast hydrolysate (Australian Biosearch), sugar (Bidvest, Australia), in the ratio of 1:4 and water was $50 \mathrm{Ml}$ [1].

- Blueberries Cultivars

First Blush 4514 and Brigitta cultivars were used in this expermient. These cultivars were obtained from 1949C Hootons Road, Tabulam New South Wales (NSW), Australia. Fruits were stored for three days under $2^{\circ} \mathrm{C}$ until used in our experiment.

\section{- Blueberries Quality Parameters}

Colour, diameter, weight, hardness, brix and acidit were studied by select the fruit randmaly from each cultivar. Colour was measured by colorimeter (CS-210 portable digital dolorimeter, diameter by millimeters vernier, weight by digital balance (PAL-BX|ACID7), hardness by fruit hardness tester (Model No GY-2) and brix, acidity by pocket brix-acidity meter (Blueberry) PAL-BX|ACID7 master kit. Three relplicate have been used in this experiment. 


\section{- Infestation and Sampling}

Flies were placed in cages as described in insect culture covered with mesh in one side. Approximately 1500 mature (11 day old) has been used in the expermient. In each cage, 300 bluberries placed and allowed for infested. Oviposition has been allowed for one day ( 24 hours) infestation. Then, the infested bluberries were replaced and clean with distilled water to remove any fly excreta. Infested fruits have been divided to three groups randomly for chemicals collection (first, second and third instars) and one group as non infested fruits. The fruits have been left for 2-3 days intervals, then, cut the blueberries to determine the instars and monitor infestation level. Juice and pulp were tested and estimate using a microscope to detect any larvae instars. For collect the VOCs, same conditions have been used for all infested blueberries. Ten blueberries were used in each sample. They selected randomly from each group. Three replicate were used in each stage of instars. After chemical sampling, all fruits were cut and recorded the number of larvae.

\section{- Volatile Collections and Analysis}

Ten blueberries placed in $100 \mathrm{~mL}$ jars. Volatile compounds collected by HS-SPME with 50/30 $\mu \mathrm{m}$ Carboxen.DVB/PDMS $(2 \mathrm{~cm})$ (Sigma-Aldrich, USA) coated. The jars have been left for 4 hours sealing time at $24^{\circ} \mathrm{C}$, then the fibre was insert into the jar to collect the chemicals. Fibre has been exposed for 1 hour as extraction time. The fibre has been inject into GC/MS for $10 \mathrm{~min}$. Chemicals were analysed by using GC-MS (7820) equipped with a detector (5977) Agilen Tech.. The column was DB, 35ms $(30 \mathrm{~m} \times 250 \mu \mathrm{m} \times 0.25 \mu \mathrm{m})$ (Santa Clara, USA). The carrier gas was helium 99.99\% (BOC, Australia). The GCMS setup as follows: flow rate was $1: 1 \mathrm{ml}$-min and splitless was $20 \mathrm{ml} / \mathrm{min}$ with $1.5 \mathrm{~min}$. The initial oven was $50^{\circ} \mathrm{C}$ which reached $250^{\circ} \mathrm{C}$ by $\left(5^{\circ} \mathrm{C}\right.$ per min). The injector port temperature was $270^{\circ} \mathrm{C}$. The total instrument run time was 45 mins. Three replicates collected from each cultivar of blueberries. Volatiles have been deconvoluted using AMDIS version 2.71, and identified by searching the NIST (2014) (US National Institute of Standards and Technology) comparied with retention index (RI) confirmation.

\section{- $\quad$ Statistical Analysis}

One way ANOVA table has been used to analysis the level of infestation. Two way ANOVA table has been used to analysis the differences between the compounds. (LSD, $\mathrm{P} \leq 0.05$ ) has been used to detemine the means between treatments. The area of each compound was divided by $10^{5}$.

\section{RESULTS AND DISCUSION}

\section{- Level of Infestation}

Infested fruits dissected immediately after collecting the VOCs samples. For the $1^{\text {st }}$ instar, it was too hard to calculate them because the larvae was very small. There are no significant differences between cultivars at the same conditions. Average \pm SE number of larvae were 13.40, 9.20 and 6.96 (first, second and third instars) respectively in first blush, while in Brigitta cultivar were 9.43, 6.10 and 5.50 respectively (Fig 1).

TABLE 1. blueberries quailty and characteriastions for First Blush and Brigitta cultivars.

\begin{tabular}{ccccccccccc}
\hline \multicolumn{10}{c}{ colour $^{\mathbf{c}}$} \\
\hline Cultivar & $\mathbf{W}(\mathbf{g})^{\mathbf{a}}$ & Diam $^{\mathbf{b}}(\mathbf{c m})$ & Red & Green & Black & hard $^{\mathbf{d}}$ & $\mathbf{R H ~ \%}$ & Brix $^{\mathbf{f}}$ & acid $^{\mathbf{g}}$ & sug $^{\mathbf{h}}$ \\
First Blush & 3.83 & 2.12 & 90.91 & 85.10 & 146.9 & 2.45 & 89.11 & 14.5 & 0.5 & 26.43 \\
Brigitta & 2.45 & 1.14 & 112.20 & 134 & 250 & 3.23 & 88.41 & 15 & 0.4 & 28.40 \\
\hline
\end{tabular}

(a)Weight; (b) diameter; (c) colour of berries; (d) hardness test; e Relative humidity; (f) brix; (g) acid and (h) sugar. 


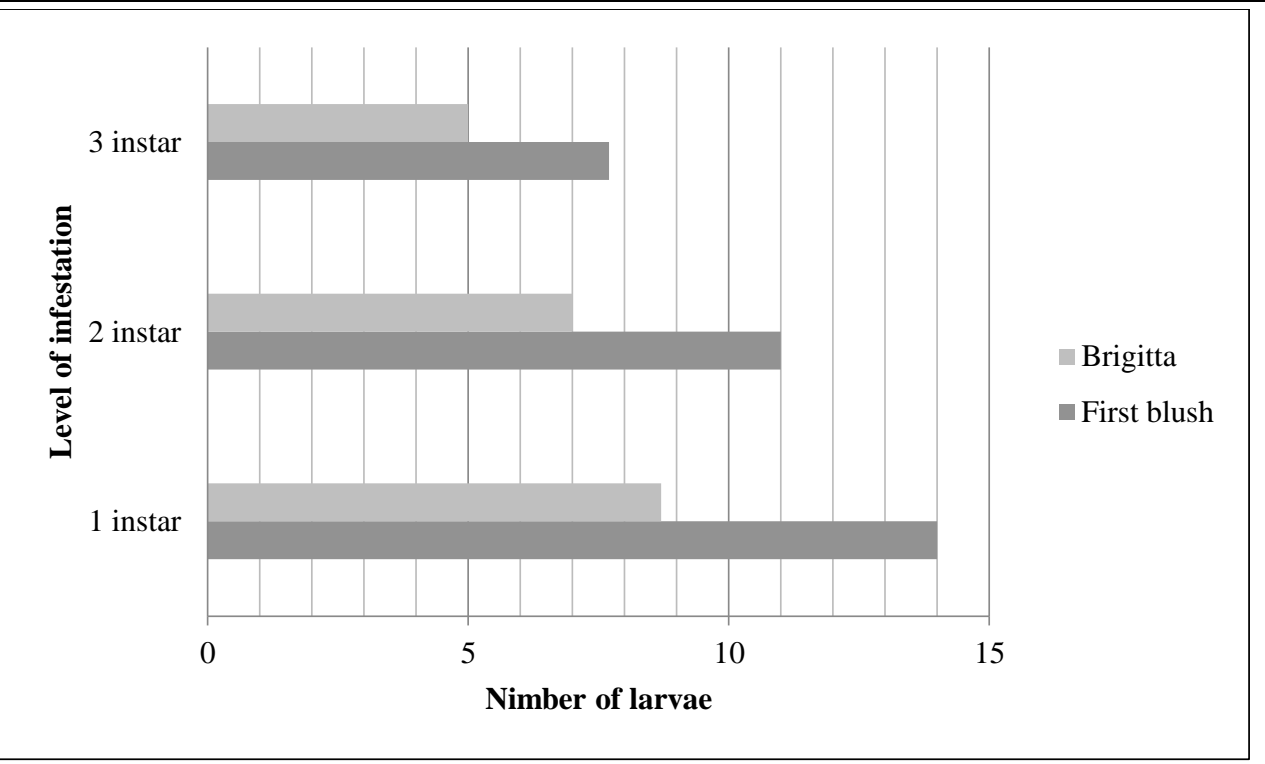

FIGURE 1. Infestation level in different bluberries cultivers.

\section{- Identification of Volatiles}

The GC-MS analysis has been detect many peaks, but some of them still a small area. Fourteen peaks recorded by the GC analysis of first blush cultivar, and 12 peaks from brigitta one. Non infested fruit showed different volatiles with infested fruits. There are significant different in some volatiles. Methyl isovalerate, butanoic acid-3 methyl-, methy ester, undecane, B-myrcene, valerena-4,7(11)-diene, caryophyllene, hexadecane cyclononasiloxane, octadecnethyl, isopimaradiene, manool oxide have been presented from first blush (Table 2) However, undecane, aznlene, 4,7-dimethyl, tridecane, 6-Methyl 1-2,3dihydro-1,4-oxathine, undecane and3-Methylbiphenyl relasead from brigitta (Table 3).

TABLE 2. Volatile compounds in First Blush 4514 cultivar infested with Medfly identify by GC-MS. Each number repesent 105.

\begin{tabular}{ccccccc}
\hline \multirow{2}{*}{$\mathbf{R T}^{\mathbf{a}}$} & Compound name $^{\mathbf{b}}$ & $\mathbf{R I}^{\mathbf{c}}$ & \multicolumn{3}{c}{ First blush $^{\mathbf{d}}$} & \multirow{2}{*}{ Non-infested $^{\mathbf{e}}$} \\
\cline { 5 - 7 } & & 721 & 23.10 & $77.33^{*}$ & 43.83 & 23.10 \\
3.82 & Isobutyl acetate & 761 & - & 32.50 & $47.02^{*}$ & 12.67 \\
6.00 & Methyl isovalerate & 820 & - & - & - & $66.15^{*}$ \\
6.02 & Butanoic acid-3 methyl-, methy ester & 824 & 44.62 & - & 38.35 & - \\
7.25 & Styrene & 914 & 32.11 & - & - & 32.10 \\
14.56 & B-myrcene & 1120 & - & - & 45.13 & - \\
21.43 & Modephene & 1416 & 16.97 & 34.60 & - & 43.87 \\
22.60 & 7-epi-silphiperfol-5 & 1448 & - & 16.02 & 28.90 & 14.76 \\
23.02 & Benzene,2,5- cyclohexadian-1 & 1449 & 45.20 & - & - & 29.19 \\
23.15 & Valerena-4,7(11)-diene & 1487 & - & $45.38^{*}$ & 32.30 & - \\
23.78 & Caryophyllene & 1494 & - & $45.32^{*}$ & - & 10.90 \\
29.68 & Cyclononasiloxane, octadecnethyl & 1858 & 21.89 & 39.31 & - & - \\
35.52 & Isopimaradiene & 1926 & - & 24.50 & 34.30 & - \\
36.83 & Manool oxide & 1992 & 25.20 & - & - & 12.89 \\
\hline
\end{tabular}

(a) retention time; (b) compound names; (c) retention index; (d) eureka cultivar; (1) first, (2) second and (3) third instars; (e) non-infested fruit. * sigmificant differences at 0.05 .

The GC-MS detect that Isobutyl acetate, Butanoic acid-3 methyl-, methy ester, Caryophyllene and Isopimaradiene from first blush cultivar. The first instar of larvae showed more chemical than others However, the third instar was the lowest level of infested fruit chemicals (Table 2). The non infested fruits indicate 6 peaks like Isobutyl acetate, Butanoic acid-3 methyl-, Styrene, Modephene, 7-epi-silphiperfol-5 and Benzene,2,5- cyclohexadian-1.

There were still some interesting area presented in infested fruit these include Butanoic acid-3 methyl-, Benzene,2,5cyclohexadian-1, and Cyclononasiloxane, octadecnethyl in first blush. Linalool, undecane, Dodecan, Naphthalene, 1 methyl, and A-elemene have bben recordrd from brigitta cultivar. The volailes presented in tables showed that there is a major differences between instars and cultivars. Some volaties detect in both cultivars (Table 1, 2). 
TABLE 3. Volatile compounds in Brigitta cultivar infested medfly identify by GC MS

\begin{tabular}{|c|c|c|c|c|c|c|}
\hline $\mathbf{R T}^{\mathrm{a}}$ & Compounds $^{b}$ & $\mathbf{R} \mathbf{I}^{\mathrm{c}}$ & & Brigitta & & Non-infested ${ }^{\mathrm{e}}$ \\
\hline 3.89 & Methyl isovalerate & 761 & - & 14.34 & 15.48 & 9.49 \\
\hline 6.02 & Butanoic acid-3 methyl-, methy ester & 824 & 11.45 & - & 43.18 & 14.21 \\
\hline 8.32 & 6-Methyl 1-2,3-dihydro-1,4-oxathine & 921 & - & $79.90 *$ & $78.19 *$ & 13.14 \\
\hline 10.87 & Mesitylene & 956 & 10.34 & - & $78.50 *$ & 12.30 \\
\hline 14.50 & Linalool & 1082 & 55.18 & - & - & 45.13 \\
\hline 14.56 & Undecane & 1100 & - & 16.55 & 11.87 & 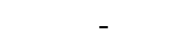 \\
\hline 17.63 & Dodecane & 1200 & 23.73 & - & - & 77.30 \\
\hline 20.43 & Naphthalene, 1 methyl-, & 1289 & 18.34 & 12.78 & - & 17.65 \\
\hline 21.07 & A-Elemene & 1334 & - & - & - & 43.45 \\
\hline 23.78 & Caryophyllene & 1494 & 44.29 & 33.26 & - & 43.76 \\
\hline 25.61 & 3-Methylbiphenyl & 1526 & - & 13.79 & $89.45 *$ & - \\
\hline 28.73 & Undecane,4,7-dimethyl & 1693 & 19.11 & - & $66.32 *$ & 10.11 \\
\hline
\end{tabular}

(a) retention time; (b) compound names; (c) retention index; (d) OPI 1111 cultivar; (1) first, (2) second and (3) third instars; (e) non-infested fruit. * significant differences at 0.05 .

The bluberries have been relaesed a different volatiles including esterified chemicals. aliphatic structures reported several kind of chemicals, specially in brigitta cultivar [14]. Butanoic acid-3 methyl- was the most important volatile in both cultivars. It has been record that d-limonene is a major volatile copmound of the aroma from most fruits. This chemical emissions increased more than other volatiles, espieclly in ripening fruits. In the experiment, butanoic acid-3 methyl-, methy ester volatile was presented in both first blush and brigitta cultivars. It is record in first and third instars.

The first level of infestation was the hardest level to detect using visual inspection. The ripening progression would be not account for the observed decrease in butanoic acid-3 methyl-, level over time. This pattern of volatiles were reported in another profile of fruits [15]. High levels of esters always presented at buleberries that infested with the medfly larvae . However, some compounds were not match with other compounds in NIST database. Additional work is needed to determine the new chemical sources (larvae, host fruit or microbial origin). Healthy fruits released small level of peak areas in some compounds like 6-Methyl 1-2,3-dihydro-1,4-oxathine and mesitylene.

Although the potentially diagnostic of larvae infestation, these still small, fast-eluting volatiles were not resolved well by the rapid GC/MS separation. As with d-limonene, elevated peak of myrcene and undecane have been shown to be correlated with wounded bluberries fruit. However, due to their low olfactory threshold, characteristic flavour notes are added to blueberry aroma such as limonene, $\beta$-myrcene and Mesitylene, also, many of the detected chemicals structures also have strong potential and supplement the characteristic of blueberries [16,17].

HS-SMPE fibre was used as reliable and fast way to decribe volatile compounds from plant samples. It was very sensitve and suitability methods $[18,19]$. As well as, the GC-MS detect the low abundance from infested fruits. At the same time, the results recorded in systemitic way [20]. Futhermore, most of the compounds that recorded from bluberries Vaccinium sp.cultivar have been reported by $[21,22,23]$. [24], found that the females of Drosophila suzukii responded preferentially to odors from Chinese bluberries to the non-infested control fruits

Vaccaro and Bouvet (2006) [25] has been used same preferences of C. Capitata female from bioassays. The results showed methanolic and hexanic extracts from fruit fly infested bluberries as compared to healty fruit or mechanically damaged fruit by using GC-MS. The qualitative and quantitive are different in volatile content profile depend on the treatments. Several compounds were elevated with infestation, including 3-carene, d-limonene, gurgenene and terpinolene [26].

\section{CONCLUSION}

In conclusion, infested fruits realesed different volatile compounds comparing to non infested blueberries Vaccinium spp. Methyl esters has been recorded low relative level for both cultivars . some volatile compounds are presented like pheromone of fruit fly $C$. capitata, which is too low in levels. The fruit fly selected fruit depends on intense, fruity, sweet. Also, characteristic blueberry flavors can be help breeders to detect medly in early infested. The results also shwed that non infested fruit relaesed different peak areas which could be used preferentially in particular environmental contexts. This profiles can help the bluberries breeders to reduce the damage of seious pests.

\section{REFERENCES}

[1] Thomas, M., J. Heppner, R. Woodruff, H. Weems, G. Steck and T. Fasulo, 2010. Mediterranean fruit fly, Ceratitis capitata (Wiedemann) (Insecta: Diptera: Tephritidae). Florida Department of Agriculture and Consumer Services, Division of Plant Industry. (2010). http://edis.ifas.ufl.edu

[2] Broughton, S., 2012. Managing Mediterranean fruit fly in backyards. Dep Agri Food (2012). www.agric.wa.gov.au

[3] Kourti, A., 2007. Estimates of gene flow from rare alleles in natural populations of medfly Ceratitis capitata (Diptera: Tephritidae). Bull Entomol. Res., 94:449-456. 
[4] Bernard, C.D.,W. Bronwyn,A. Chris, M. Mathew and D. Rob, 2015. Definition of and management strategies for areas of low pest prevalence for Queensland fruit fly Bactrocera tryoni Froggatt. Crop Prot., 72:41-46.

[5] Pimentel, D.,1995. Amounts of pesticides reaching target pests: Environmental impacts and ethics. J. Agri. Envir.Ethics., 8:17-29.

[6] Bernadine, C.S., 2007. Horticultural practices of growing highbush blueberries in the Ever-expanding U.S. and global scene. J. Amer. Pomol. Soc., 61:148-150.

[7] Silva, M.A., G. Bezerra-Silva, J.D.Vendramim, M.R. Forim and I.C. Sá., 2015. Threshold concentration of limonoids (Azamax) for preventing infestation by Mediterranean Fruit Fly (Diptera: Tephritidae). J. Eco. Entomol., 108:629-639.

[8] Burhanettin, I.B., K. Ayzin , T. Emine and K. Ebru., 2015. Volatile and some fruit quality characteristics of new promising peach genotypes. Acta. Sci. Polon. Horto. Cult., 14:12.

[9] Giulia, G., G. Benelli, G. Flamini, J.P. Michaud and A. Canala., 2016. Innate and learned responses of the Tephritid parasitoid Psyttalia concolor (Hymenoptera: Braconidae) to olive volatiles induced by Bactrocera oleae (Diptera: Tephritidae) infestation. J. Eco. Entomol., 109: 2272-2280.

[10] Kirsten, S., R. Isaacs, J. Wise and L. Larry., 2003. Protection of fruit against infestation by apple maggot and blueberry maggot (Diptera: Tephritidae) using compounds containing spinosad. J. Eco. Entoml., 98:432-437.

[11] Liburd, O.E., S. Polavarapu, S. Alm and R. Casagrande., 2000. Effect of trap size, placement, and age on captures of blueberry maggot flies (Diptera: Tephritidae). J. Eco. Entomol., 93: 1452-1468.

[12] Liburd, O.E., S. Alm and R. Casagrande., 1998. Susceptibility of highbush blueberry cultivars to larval infestation by Rhagoletis mendax (Diptera: Tephritidae). Envir. Entomol., 27: 817-822.

[13] Tochen, D.T., N. Dalton, H.P. Christopher and V.M. Shearer., 2014. Temperature-related Development and population parameters for Drosophila suzukii (Diptera: Drosophilidae) on cherry and blueberry. Envir. Entomol., 43:501-510.

[14] Liburd, O.E., S.R. Alm, R.A. Casagrande and S. Polavarapu, 1998. Effect of trap color, bait, shape and orientation in attraction of blueberry maggot flies. J. Eco. Entomol., 91:243-249.

[15] Lugemwa, F.L., W. Lwande, M. Bentley, M. Mendel A. 1989. Alford AR, Volatiles of wild blueberry, Vaccinium augustifolium: Possible attractants for the blueberry maggot fly, Rhagoletis mendax. J. Agric. Food Chem., 37: 232-238.

[16] Warthen, J.D., C. Lee, E. Jang, D. Lance and D. McInnis, 1997. Volatile potential attractants from ripe coffee fruit for the female Mediterranean fruit fly. J. Chem. Ecol., 23:1891-1900.

[17] Aluja, M. and R. Mangan, 2008. Fruit fly (Diptera: Tephritidae) host status determination: critical conceptual, methodological, and regulatory considerations. Annu. Rev. Entomol., 53:473-502.

[18] Brazelton, D. and B. Strik, 2007. Perspective on the U.S. and global blueberry industry. J. Amer. Pomol. Soc., 61:144-147.

[19] Sampson, B.J., D. Marshall, B. Smith, S. Stringer, C. Werle, D. Magee and J. Adamczyk, 2017. Erythritol and lufenuron detrimentally alter age structure of wild Drosophila suzukii (Diptera: Drosophilidae) populations in blueberry and blackberry. J. Eco. Entomol., 110:530-534.

[20] Follett, P., J. Armstrong and F. Zee, 2009. Host status of blueberry to invasive tephritid fruit flies in Hawaii. J. Eco.Entomol., 102:1859-1863.

[21] Von Sydow, E. and K. Anjou, 1969. Aroma of blueberries (Vaccinium myrtillus). Identification of volatile compounds. Leben. Wiss. Technol., 2:78-82.

[22] Horvat, R.J., W.S. Schlotzhauer, O.T. Chortyk, S.F. Nottingham and J.A. Payne, 1996. Comparison of volatile compounds from rabbit eye blueberry (Vaccinium ashei) and Deerberry (V. stamineum) during maturation. J. Essen. Oil. Res., 8:645-648.

[23] Polashock, J.J., R.A. Saftner and M. Kramer, 2007. Postharvest highbush blueberry fruit antimicrobial volatile profiles in relation to anthracnose fruit rot resistance. J. Amer. Soc. Hort. Sci., 132:859-868.

[24] Yan, L., D.Wenxia, Z. Feng, K. Marc, G. Frans, Z. Jinping, C. Li, X. Chun, 2018. Identification of active components from volatiles of Chinese bayberry, Myrica rubra attractive to Drosophila suzukii. Arthr. Plant Interact., 12:435-443.

[25] Vaccaro, N.C. and J.P. Bouvet, 2006. Presence of Ceratitis capitata (Wied.) and A. fraterculus (Wied.) in blueberries (Vaccinium spp.) of the Department of Concordia, Entre Ríos and in the Department of Curuzú Cuatía, Corrientes, Argentina. 7th International Symposium on Fruit Flies of Economic Importance, Salvador, Brazil, 10-15 September, (2006).

[26] Baloga, D.W., N. Vorsa and L. Lawter, 1995. Dynamic headspace gas chromatography-mass spectrometry analysis of volatile flavor compounds from wild diploid blueberry species. In: Rousseff R.L. and Leahy M.M. (eds.), Fruit Flavors: Biogenesis, Characterization and Authentication, ACS Symposium Series 596, Oxford University Press, USA, pp. ( 1995) 235. http://doi.10.1021/jf991385b 